\title{
Multiple Levels of Social Disadvantage and Links to Obesity in Adolescence and Young Adulthood
}

Hedwig Lee, PhDa Kathleen M. Harris, PhD b Joyce Lee, MD, MPH

ABSTRACT

BACKGROUND: The rise in adolescent obesity has become a public health concern, especially because of its impact on disadvantaged youth. This article examines the role of disadvantage at the family-, peer-, school-, and neighborhood-level, to determine which contexts are related to obesity in adolescence and young adulthood.

METHODS: We analyzed longitudinal data from Waves I (1994-1995), II (1996), and III (2001-2002) of the National Longitudinal Study of Adolescent Health, a nationally representative population-based sample of adolescents in grades 7-12 in 1995 who were followed into young adulthood. We assessed the relationship between obesity in adolescence and young adulthood, and disadvantage (measured by low parent education in adolescence) at the family-, peer-, school-, and neighborhood-level using multilevel logistic regression.

RESULTS: When all levels of disadvantage were modeled simultaneously, school-level disadvantage was significantly associated with obesity in adolescence for males and females and family-level disadvantage was significantly associated with obesity in young adulthood for females.

CONCLUSIONS: Schools may serve as a primary setting for obesity prevention efforts. Because obesity in adolescence tracks into adulthood, it is important to consider prevention efforts at this stage in the life course, in addition to early childhood, particularly among disadvantaged populations.

Keywords: child and adolescent health; physical fitness and sport; public health.

Citation: Lee H, Harris KM, Lee J. Multiple levels of social disadvantage and links to obesity in adolescence and young adulthood. J Sch Health. 2013; 83: 139-149.

Received on May 16, 2012

Accepted on August 9, 2012

$\mathrm{T}$ here is a strikingly high prevalence of adolescent obesity among underprivileged groups, including racial/ethnic minorities and those living in households affected by poverty and low levels of education. ${ }^{1}$ These vulnerable populations of adolescents not only contend with disadvantage at the family level but also at the peer group, neighborhood, and school level. For example, disadvantaged adolescents navigate environments where their classmates and friends may also be disadvantaged, ${ }^{2}$ leading to reinforcement of unhealthy behaviors. ${ }^{3}$ They may attend disadvantaged schools with less access to physical education programs or healthy foods. ${ }^{4}$ Finally, they may live in disadvantaged neighborhoods that do not have grocery stores that provide affordable fruits and vegetables and lack safe recreation sites to support physical activity. ${ }^{5}$ These factors warrant the consideration of multiple levels of disadvantage to

aAssistant Professor, (hedylee@u.washington.edu), Department of Sociology, University of Washington, 211 Savery Hall, Box 353340, Seattle, WA $98195-3340$.

bProfessor, (kathie_harris@unc.edu), Department of Sociology, Carolina Population Center, University of North Carolina at Chapel Hill, 403 University Square East, 123 W. Franklin Street, Chapel Hill, NC 27516.

'Assistant Professor, (joyclee@umich.edu), Pediatric Endocrinology and Health Services Research, Child Health Evaluation and Research Unit, University of Michigan, 300 NIB, Room 6E18, Campus Box 5456, Ann Arbor, Ml 48109-5456.

Address correspondence to: Hedwig Lee, Assistant Professor, (hedylee@u.washington.edu), Department of Sociology, University of Washington, 211 Savery Hall, Box 353340 , Seattle, WA 98195-3340.

This research uses data from Add Health, a program project directed by K M. H. and designed by J. Richard Udry, Peter S. Bearman, and K. M. H. at the University of North Carolina at Chapel Hill, and funded by grant P01-HD31921 from the Eunice Kennedy Shriver National Institute of Child Health and Human Development, with cooperative funding from 23 other federal agencies and foundations. Special acknowledgment is due Ronald R. Rindfuss and Barbara Entwisle for assistance in the original design. Information on how to obtain the Add Health data is available on the Add Health website (http://www.cpc.unc.edu/addhealth). The funding sources had no role in the study design; collection, analysis, and interpretation of data; writing of the report; or the decision to submit the article for publication. 
understand the role of disadvantage on obesity during this period.

The ecological model of human development emphasizes that individuals are influenced by the environments in which they are embedded, including the family, peer group, neighborhood, and school. ${ }^{6}$ These environments are conceptualized as nested systems and represent increasingly larger contexts of the social environment in which adolescents live, learn, mature, and interact with others. They impact available resources and opportunities, relationships and ties to others, and are subject to accepted norms of behavior. ${ }^{7}$ All levels operate together to influence adolescent development, including health behaviors and health status such as obesity.

Although there is a body of research linking family, peer, neighborhood, and school contexts to obesity in childhood and adolescence, prior research has not examined all these contexts simultaneously. ${ }^{8-17}$ Furthermore, most research has utilized cross-sectional rather than longitudinal data, overlooking how these relationships may change over time. ${ }^{18}$ Because social disadvantage in one context is correlated with disadvantage in multiple contexts and across time, to fully understand how socioeconomic disadvantage is related to obesity requires modeling multiple levels of disadvantage across the early life course. ${ }^{19,20}$

Adolescence and young adulthood are critical stages in the life course during which lifestyle and healthrelated behaviors are established and the risk of obesity is high. ${ }^{21-23}$ Socioeconomic disparities in obesity increase dramatically during these periods and often persistent into later adulthood, disproportionately impacting the likelihood of chronic disease and further compounding economic well-being for disadvantaged populations. ${ }^{24-28}$ Adolescence and young adulthood are life stages when young people have more autonomy and control in decision-making regarding their behaviors, including those related to their health, and are especially influenced by the expanding social environments in which they are embedded. ${ }^{19}$

Our objective was to investigate the unique influence of various levels of social disadvantage simultaneously, using nationally representative longitudinal data. We created measures of socioeconomic disadvantage across multiple contexts, including the family, peer, school and neighborhood, and used multilevel modeling, a methodology that allows for the simultaneous examination of the effects of group-level and individual-level predictors ${ }^{29}$ to determine what levels of context were significantly associated with obesity during adolescence and young adulthood.

This study contributes to the literature by modeling multiple levels of disadvantage and its relationship to obesity across the early life course. It also serves to ascertain the contexts most salient to obesity in early life. A better understanding of the social contexts in which adolescents are embedded and how they are associated with obesity may point the field to where opportunities for interventions are relatively more strategic to reduce the risk of obesity in adolescence and young adulthood.

\section{METHODS}

\section{Participants}

We used the National Longitudinal Study of Adolescent Health (Add Health), a nationally representative study of adolescents in grades 7-12 in 1995 designed to explore the influence of social context on health and health behaviors. ${ }^{30}$ Schools were selected using a stratified cluster design, and adolescents $(\mathrm{N}=20,745)$ and a parent $(\mathrm{N}=17,713)$ were randomly selected from school rosters for the Wave I (WI) in-home interview (1995). Adolescents were re-interviewed in Waves II (WII:1996), III (WIII:2001-2002), and IV (WIV:20072009). Seniors in WI were not followed up in WII as part of the Add Health design but were re-interviewed in WIII and WIV. ${ }^{30}$ Over $70 \%$ of sampled schools participated, with adolescent interview completion rates of $78.9 \%, 88.6 \%, 77.4 \%$, and $80.3 \%$ for WI, WII, WIII, and WIV, respectively, and $85 \%$ parent participation.

Our sample included individuals who participated in WI-WIII $(\mathrm{N}=10,828)$, had parent, peer, neighborhood, and school information, and measured height and weight by trained interviewers in WII and WIII. We did not include self-reported height and weight from WI because of the well-known bias associated with self-reported measures. ${ }^{31,32}$ Additional exclusions included seriously disabled and pregnant $(\mathrm{N}=261)$ adolescents and those with no friendship information $(\mathrm{N}=1121)$, leaving a sample of 6321 . Compared with individuals not included, individuals in the sample were younger $(14.85[\mathrm{SE}=0.13]$ versus 15.78 [0.12]; $\mathrm{p}<.01)$, more likely to be female $(0.53$ [0.01] versus $0.47[0.01] ; \mathrm{p}<.01)$, and less likely to be Black $(0.13$ [0.02] versus .17 [0.02]; $p<.01)$ and Hispanic $(0.08$ [0.01] versus $0.14[0.02] ; p<.01)$, to have received welfare $(0.26$ [0.01] versus 0.30 [0.02]; $p<.01)$, and to have had a highest educated parent with a high school degree or less (0.41 [0.02] versus 0.48 [0.02]; $p<.01)$.

\section{Instruments}

Dependent Variables. Body mass index (BMI, $\mathrm{kg} / \mathrm{m}^{2}$ ) was calculated using the International Obesity Task Force (IOTF) developed BMI curves, which link childhood BMI percentiles to adult cutoffs. ${ }^{33}$ Individuals were classified as obese if their BMI fell at or above the age- and sex-specific IOTF obesity cut point in adolescence or the adult BMI cut point of $30 \mathrm{~kg} / \mathrm{m}^{2}$ in adulthood.

Independent Variables and Controls: Individual/ Family-Level Variables. Individual-/family-level variables from WI included age, sex, race/ethnicity 
(non-Hispanic white [referent], black, Asian, Hispanic, other), family structure (two biological/adoptive parents [referent], step-family, single-mother, singlefather, surrogate/foster parents), and self-reported parental obesity (controlling for genetic predisposition to obesity). ${ }^{34}$ Race/ethnicity was included as a control because of the confounding of race/ethnicity and socioeconomic status (SES). ${ }^{35}$

Social Disadvantage Covariates. We chose parent education as our measure of disadvantage at each level of social context for the following reasons. First, models that include multiple measures of SES aggregated at the same level (ie, neighborhood poverty, unemployment, and education) would introduce multicollinearity. Second, education has a large and persistent association with health behaviors and health status. ${ }^{36}$ Third, unlike parent education, $30 \%$ of the sample had missing parental income information. Last, there is precedent for using parent education in the social science literature. Previous research has used parent/adult education at the family, peer, school, and neighborhood levels as a proxy for SES when studying multiple child and adolescent health outcomes, including obesity. ${ }^{12,14,37,38}$

Family-Level Disadvantage. To classify family disadvantage, we included a measure of welfare/poverty status, defined as any welfare receipt before the age of 18 or family income less than poverty level (income less than $\$ 16,000$ [roughly the poverty level for a family of 4 in 1994]), and parent education, defined as receipt of a high school degree or less for the highest educated parent. This definition was based on a growing body of literature linking poverty status and public assistance receipt to obesity. ${ }^{39}$ The inclusion of welfare also mitigates the problem of item nonresponse for parental income. ${ }^{40}$

Peer-Level Disadvantage. In Add Health, students nominated up to 5 male and 5 female friends within their school, which could be linked back to nominated peers' own questionnaires to determine peer group characteristics. Peer-level disadvantage was a continuous measure of the percentage of individuals from the peer group with a (highest educated) parent with a high school degree or less; ie, if a respondent nominated 8 friends and 4 had a parent who received a high school degree or less, then $50 \%$ (4/8) of his/her peer group was classified as disadvantaged.

School-Level Disadvantage. School-level disadvantage was a continuous measure of the percentage of students in a respondent's school with a (highest educated) parent with a high school degree or less; ie, if a respondent's school contains 1000 students and 200 of the students in that school had a parent with a high school degree or less, then $20 \%(200 / 1000)$ of his/her school was classified as disadvantaged.
Neighborhood-Level Disadvantage. Contextual data containing census information on the characteristics of the neighborhoods in which respondents lived in WI were linked to each respondent. Neighborhood was defined by census block group. ${ }^{41}$ Neighborhoodlevel disadvantage was a continuous measure of the proportion of individuals in a neighborhood aged 25 years and over with no high school diploma. A neighborhood-level measure of the proportion of individuals in a neighborhood aged $\geq 25$ years with a high school degree or less (similar to our other contextual measures of parent education) was not available. We also included a measure of urbanicity (completely urbanized versus areas including rural regions) to account for regional differences in the prevalence of disadvantage and obesity. ${ }^{42,43}$

\section{Data Analysis}

Means and standard errors for descriptive statistics were weighted to account for unequal probability of selection and adjusted for survey design effects to yield nationally representative estimates. Multilevel logistic regression with random effects (2-level random intercepts model) was used for bivariate and multivariate analysis. ${ }^{29}$ Multilevel models account for the nesting of individuals (peers and neighborhoods) within schools. Multilevel modeling is used to investigate the unique influence of each level of disadvantage on obesity risk, adjusting for the lack of independence among individuals who share the same context. ${ }^{29}$ We employed a 2-level model: individuals (and their families) represent level 1 and schools represent level 2. Peer context is associated with individuals (level 1) given that peer groups represent respondents' nominations within their school. In the school-based design of Add Health, neighborhoods (block groups) are nested within schools (level 2). ${ }^{30}$ High schools and the associated feeder school (middle or junior high) drew from multiple neighborhoods within the school boundary. ${ }^{30}$ Multilevel models adjust the variance estimates for the non-independence of adolescents who share the same school context (ie, the larger spatial context) and, by extension, adjust for clustering of adolescents within neighborhoods.

We examined the bivariate association between each level of disadvantage at WI (adolescence) and obesity at WII (adolescence), and WIII (young adulthood), separately. Multivariate multilevel modeling was used to investigate the independent association of each level of disadvantage with obesity risk in adolescence (WII) and adulthood (WIII). Model 1 (null model) included a constant term and determined school-level variability in obesity across schools, also known as the intraclass correlation (ICC). Model 2 included the individual- and family-level (level 1) variables for race/ethnicity, age, parent obesity, family 
Table 1. Variable Means and Standard Errors by Sex*

\begin{tabular}{|c|c|c|c|c|}
\hline & \multicolumn{2}{|c|}{ Female } & \multicolumn{2}{|c|}{ Male } \\
\hline & Mean & SE & Mean & SE \\
\hline \multicolumn{5}{|l|}{ Outcomes } \\
\hline \multicolumn{5}{|l|}{ Obesity (\%) } \\
\hline Obese at Wave II & 0.10 & 0.01 & 0.12 & 0.01 \\
\hline Obese at Wave III & 0.23 & 0.01 & 0.22 & 0.01 \\
\hline \multirow{2}{*}{\multicolumn{5}{|c|}{$\begin{array}{l}\text { Individual-level measures } \\
\text { Race/Ethnicity (\%) }\end{array}$}} \\
\hline & & & & \\
\hline Non-Hispanic White (Reference Category) & 0.71 & 0.03 & 0.72 & 0.03 \\
\hline Non-Hispanic Black & 0.16 & 0.02 & 0.12 & 0.02 \\
\hline Hispanic & 0.08 & 0.01 & 0.09 & 0.02 \\
\hline Non-Hispanic Asian & 0.03 & 0.01 & 0.05 & 0.01 \\
\hline Non-Hispanic Other & 0.01 & 0.00 & 0.02 & 0.00 \\
\hline Age (years) & 14.81 & 0.12 & 14.93 & 0.14 \\
\hline Parent Obese (\%) & 0.21 & 0.01 & 0.22 & 0.01 \\
\hline Missing report of parent obese & 0.09 & 0.01 & 0.08 & 0.01 \\
\hline \multicolumn{5}{|l|}{ Family-level measures } \\
\hline Welfare status and/or poverty status (\%) & 0.27 & 0.02 & 0.25 & 0.02 \\
\hline $\begin{array}{l}\text { Parent education high school or less (\%) } \\
\text { Family structure (\%) }\end{array}$ & 0.42 & 0.02 & 0.40 & 0.02 \\
\hline Two biological parents (Reference category) & 0.60 & 0.01 & 0.63 & 0.02 \\
\hline Step family & 0.16 & 0.01 & 0.16 & 0.01 \\
\hline Single mother & 0.19 & 0.01 & 0.16 & 0.01 \\
\hline Single father & 0.02 & 0.00 & 0.03 & 0.00 \\
\hline Other family structure & 0.03 & 0.00 & 0.02 & 0.00 \\
\hline \multicolumn{5}{|l|}{ Peer-level measures } \\
\hline Parent education high school or less (\%) & 0.42 & 0.01 & 0.41 & 0.02 \\
\hline \multicolumn{5}{|l|}{ School-level measures } \\
\hline Parent education high school or less (\%) & 0.44 & 0.01 & 0.44 & 0.01 \\
\hline \multicolumn{5}{|l|}{ Neighborhood-level risk } \\
\hline Adult education less than high school (\%) & 0.27 & 0.01 & 0.26 & 0.01 \\
\hline Urban (\%) & 0.45 & 0.05 & 0.43 & 0.05 \\
\hline N & 3470 & & 2851 & \\
\hline
\end{tabular}

*Data are weighted.

structure, and family-level disadvantage. For subsequent models, we included school-level disadvantage (level 2) (Model 3), neighborhood-level variables (Model 4), and peer-level disadvantage (Model 5). By simultaneously examining school-, neighborhood-, peer-, and individual-/family-level disadvantage in Model 5, we were able to differentiate between associations related to the attributes of the school (level 2) versus associations related to the attributes of the individual/family (level 1), while accounting for the composition of peer and neighborhood disadvantage. In models where WIII obesity was the outcome, we also controlled for obesity at WII. Because results do not differ qualitatively between weighted and unweighted models, we present unweighted bivariate/multivariate results. ${ }^{44}$ We performed sex-stratified analyses, given that disadvantage might operate differently in influencing obesity risk for male and female adolescents. ${ }^{9,13,45}$ We used Stata 9 (StataCorp LP, College Station, TX) for all analyses. Correlations across measures of family-, school-, peer-, and neighborhoodlevel disadvantage were moderate to low, ranging from .25 to .49 .

\section{RESULTS}

\section{Sample Characteristics}

Table 1 describes demographic characteristics of the sample, with a slightly higher proportion of females and a racial/ethnic distribution consistent with national estimates. Obesity prevalence doubled from WII to WIII. Socioeconomic composition of respondents' peers and school, measured by parent education, were similar to national school estimates of percentage of students eligible for free or reducedprice lunch $(37.8 \%) .{ }^{46,47}$ Table 2 shows the bivariate relationships (odds ratios) between each measure of disadvantage and obesity in adolescence (WII) and young adulthood (WIII) (which includes a lagged measure of WII obesity) by sex. Generally, disadvantage at each level of context was associated with increased odds of being obese. Tables 3 and 4 provide the multivariate multilevel odds ratios results for obesity in adolescence (WII) and young adulthood (WIII) by sex.

\section{Obesity in Adolescence (WII) (Females)}

About $8 \%$ of the variance in obesity in adolescence was located between schools $($ ICC $=0.077$; $\mathrm{SE}=0.027$ ) (Model 1 null model not shown). Family-level disadvantage was associated with obesity, as well as Black race, older age, and having an obese parent (Model 2). School-level disadvantage was positively related to obesity at WII, reducing familylevel disadvantage to insignificance in Model 3. Neither neighborhood-level disadvantage (Model 4) nor peerlevel disadvantage (Model 5) were significantly related to obesity. School-level disadvantage remained significantly related to obesity across all models.

\section{Obesity in Young Adulthood (WIII) (Females)}

About $6 \%$ of the variance in obesity in young adulthood was located between schools (ICC $=0.060$; $\mathrm{SE}=0.016)$ (Model 1 not shown). Obesity in adolescence, having an obese parent, Black and other race, and family-level disadvantage were significantly associated with higher odds of obesity in young adulthood (Model 2). Asian race was associated with lower odds of obesity. School-level disadvantage was significantly related to obesity and slightly reduced the magnitude of the other significant variables in Model 3. However, the inclusion of neighborhood-level disadvantage reduced the school-level disadvantage to insignificance (Model 4). Peer-level disadvantage was not significantly related to obesity (Model 5). When examining all levels of social disadvantage simultaneously, family-level disadvantage remained significantly related to obesity.

\section{Obesity in Adolescence (WII) (Males)}

About $4 \%$ of variance in obesity in adolescence was located between schools $($ ICC $=0.043 ; \mathrm{SE}=0.022)$ 
Table 2. Bivariate Associations between Disadvantage and Obesity Status in Adolescence (WII) and Young Adulthood (WIII) by Sex ${ }^{\dagger}$

\begin{tabular}{|c|c|c|c|c|}
\hline & \multicolumn{2}{|c|}{ Female } & \multicolumn{2}{|c|}{ Male } \\
\hline & $\begin{array}{c}\text { Obese Wave II } \\
\text { OR }(95 \% \mathrm{CI})\end{array}$ & $\begin{array}{c}\text { Obese Wave III } \\
\text { OR }(95 \% \mathrm{CI})\end{array}$ & $\begin{array}{c}\text { Obese Wave II } \\
\text { OR }(95 \% \mathrm{CI})\end{array}$ & $\begin{array}{c}\text { Obese Wave III } \\
\text { OR }(95 \% \mathrm{CI})\end{array}$ \\
\hline \multicolumn{5}{|l|}{ Family-level measures } \\
\hline Welfare/Poverty status & $1.50^{* *}(1.17-1.92)$ & $1.80^{* * *}(1.46-2.22)$ & $1.37^{*}(1.06-1.78)$ & $1.16(0.91-1.48)$ \\
\hline Parent education high school or less & $1.34^{*}(1.06-1.70)$ & $1.55^{* * *}(1.27-1.89)$ & $1.38^{* *}(1.09-1.76)$ & $1.33^{*}(1.06-1.65)$ \\
\hline \multicolumn{5}{|l|}{ Peer-level measures } \\
\hline Parent education high school or less & $1.96^{* * *}(1.36-2.84)$ & $1.52^{* *}(1.11-2.08)$ & $1.71^{* *}(1.19-2.46)$ & $1.19(0.85-1.65)$ \\
\hline \multicolumn{5}{|l|}{ School-level measures } \\
\hline Parent education high school or less & $9.20^{* * *}(3.69-22.96)$ & $3.93^{* * *}(1.89-8.14)$ & $10.73^{* * *}(4.55-25.31)$ & $2.25^{*}(1.04-4.90)$ \\
\hline \multicolumn{5}{|l|}{ Neighborhood-level measure } \\
\hline Adult education less than high school & $5.95^{* * *}(2.69-13.17)$ & $3.46^{* * *}(1.80-6.65)$ & $3.38^{* *}(1.48-7.69)$ & $2.65^{*}(1.26-5.55)$ \\
\hline $\mathrm{N}$ & 3470 & 3470 & 2851 & 2851 \\
\hline
\end{tabular}

$\mathrm{OR}$, odds ratio; $\mathrm{Cl}$, confidence interval.

* Significant at .05 level.

** Significant at .01 level.

*** Significant at .001 level.

${ }^{\dagger}$ Data are unweighted. Obese WIII models control for obese at WII.

(Model 1 not shown). Only parent obesity and family-level disadvantage were significantly related to obesity in Model 2. School-level disadvantage in Model 3 was significantly related to obesity, reducing family-level disadvantage to insignificance. Neighborhood-level disadvantage (Model 4) and peerlevel disadvantage (Model 5) were not significantly related to obesity. Again, school-level disadvantage remained significantly related to obesity across all models.

\section{Obesity in Young Adulthood (WIII) (Males)}

About $2 \%$ of the variance in obesity in young adulthood was located between schools (ICC $=0.023$; $\mathrm{SE}=0.011)$ (Model 1 not shown). Obesity in adolescence, parent obesity, family-level disadvantage, and age were significantly related to obesity in young adulthood (Model 2). In Model 3, the inclusion of school-level disadvantage reduced family-level disadvantage to insignificance; however, school-level disadvantage was not significantly related to obesity. Neighborhood-level disadvantage (Model 4) and peerlevel disadvantage (Model 5) were not significantly related to obesity.

\section{DISCUSSION}

We simultaneously assessed the relationship between multiple levels of disadvantage (family-, peer-, school-, and neighborhood-level disadvantage) during adolescence with the risk of obesity in adolescence and young adulthood using multilevel models. Our results showed that when all levels of disadvantage were included, only school-level disadvantage remained significantly associated with obesity in adolescence for both males and females. With our data, we could not identify what aspects of the school environment may be contributing to obesity; however, our findings could provide support for prioritization of schools as a primary setting for obesity prevention efforts, consistent with the recommendations of the Institute of Medicine (IOM) Committee on Prevention of Obesity in Children. ${ }^{48}$ Policies for improving school nutrition and increasing physical activity may therefore be particularly salient in the national effort to reduce rates of adolescent obesity. ${ }^{21,48}$

Our findings are consistent with previous studies that have found school-level disadvantage to be an important determinant of BMI in adolescence. In a multilevel analysis using WI Add Health data, Richmond and colleagues ${ }^{13,44}$ found that school-level disadvantage was associated with levels of physical activity as well as BMI among adolescents. They controlled for family SES, but did not account for neighborhood disadvantage or other levels of social context relevant to adolescence, such as peer groups. In a school-based sample of Canadian adolescents in grades $6-12$, Janssen and colleagues ${ }^{12}$ also found that area-level SES measures were associated with obesity and physical inactivity after accounting for family SES. A recent review discusses additional studies that examine the association between neighborhood disadvantage and child adiposity. ${ }^{18}$ However, most of these studies were based on cross-sectional, rather than longitudinal analyses, limiting their ability to sort out the directionality of these relationships. ${ }^{18}$

We found that school-level disadvantage in adolescence was not significantly associated with obesity by the time the Add Health cohort reached young adulthood (WIII). This is not surprising given that individuals in WIII were 6-7 years beyond secondary school. Schools are an important social context in adolescence, but by young adulthood, individuals have 


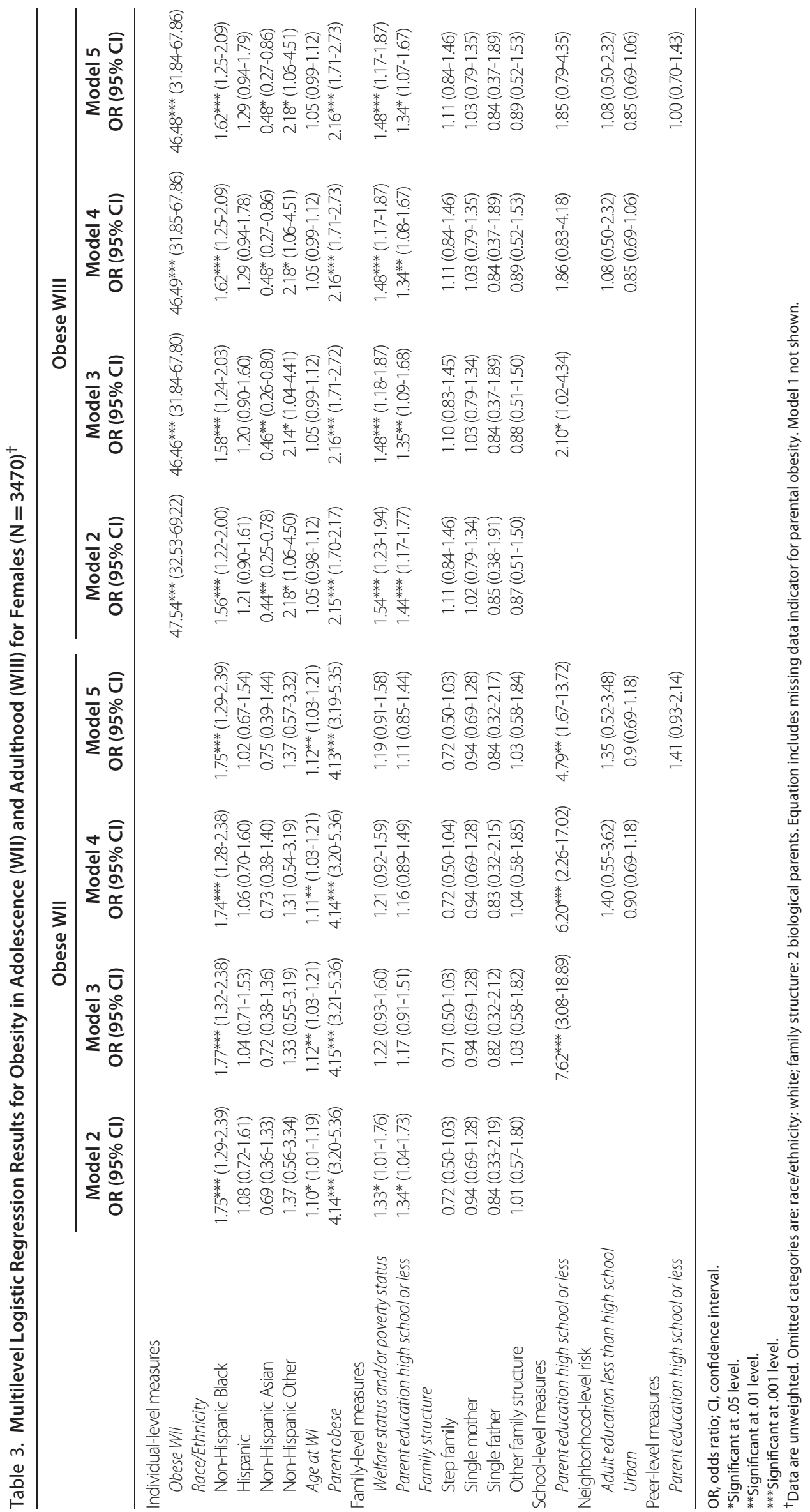




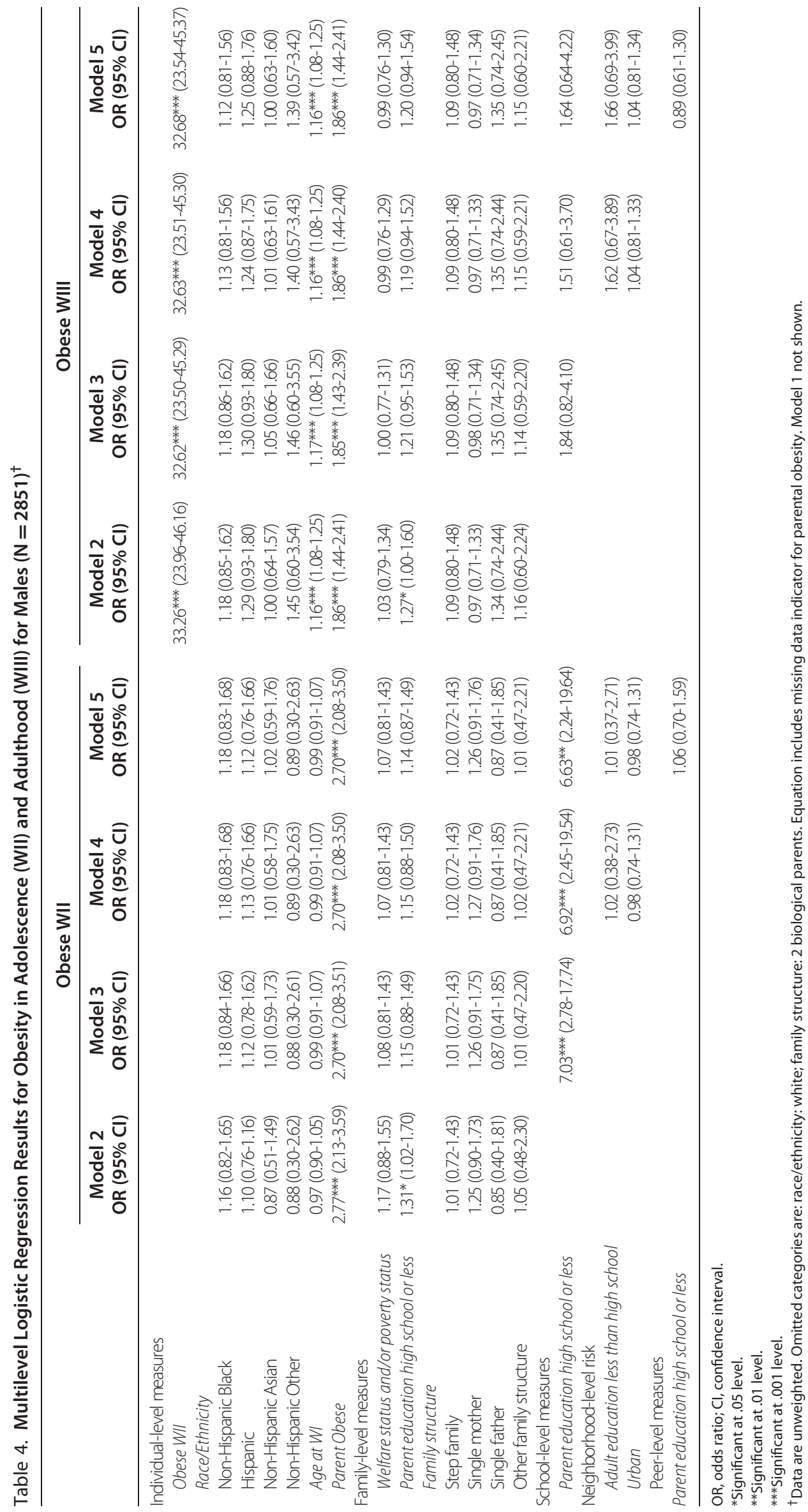


entered/completed college, entered the work setting, and may be involved in stable romantic relationships.

Our finding that family-level disadvantage remained significantly related to obesity for young adult females highlights the potentially important role of family and, in particular, parents on long-term health outcomes. Studies show that parents have a strong influence on obesity-related lifestyle behaviors during childhood. ${ }^{48}$ Therefore, we speculate that this influence, whether positive or negative, can persist into adulthood. In contrast, for males, we found no significant relationships between any level of disadvantage and obesity in adulthood, which is consistent with previous research which has shown that men's obesity status is less sensitive to measures of SES. ${ }^{49}$ These gender differences remain largely unexplained and are an important area for future research. These patterns may reflect gender differences in strategies used to cope with stress resulting from social disadvantage. For example, whereas young males may be more likely to use violence and physical activity, females may turn to sedentary behaviors and overeating as coping mechanisms-behaviors that increase the likelihood of obesity incidence. ${ }^{50,51}$ However, more empirical research is needed to test these postulations.

Interestingly, although peer and neighborhood contexts were significantly related to obesity in bivariate models, they were not significantly related to obesity in models that included both familyand school-level disadvantage. This suggests that the school context may convey more appearancebased influence, which varies by social disadvantage, whereas peer influence is based more on social interaction (ie, more relevant for delinquency, sexual behavior, substance use). The neighborhood may simply be a less salient social environment for adolescents, because adolescents spend a majority of time in school and build their social networks there. This may also be the case in Add Health because multiple neighborhoods are represented in a single school. Indeed, the correlation between school-level and neighborhood-level disadvantage in this analysis was .47 for females and .49 for males. The school environment has been linked to multiple health outcomes and behaviors in addition to weight status, such as asthma, ${ }^{52}$ depression, ${ }^{53}$ and dieting, ${ }^{3}$ underscoring the importance of this context for influencing adolescent health.

\section{Limitations}

Limitations of our analysis include the use of schoolbased peer information. Because peer composition of disadvantage tends to be very similar to school composition of disadvantage in this sample (correlation $=.46$ females; 45 males), school-based peers may serve as a proxy for the school environment. Information on peers outside of the schools that adolescents attended may have provided different results. In addition, selection bias can occur at the peer level. It is possible that peers exert little influence on individuals, but rather individuals select friends that are similar to them (eg, rich students choose rich friends).${ }^{54}$ However, this type of selection would overstate the influence of peers. This is less of a concern given that peer context was not significant in this analysis. Despite this limitation, our peer measures are more valid and do not suffer from self-reflection bias given they are based on actual peer responses than on respondent reports of peer characteristics.

We acknowledge that selection could also occur at the neighborhood and school level. Parents with attributes that are not easily observed may have a reason to choose a particular school or neighborhood. ${ }^{55}$ This is problematic because instead of capturing true contextual effects of neighborhoods and schools, we may have captured differential selection into schools and neighborhoods or unmeasured factors that affects the choice of both the neighborhood (and/or the school) and one's health. In an attempt to minimize selection bias, we controlled for family background characteristics associated with intentional selection into schools and neighborhoods, and also associated with health, such as parent obesity. We also ran analysis using additional measures of school-, peer-, and neighborhood-level disadvantage including aggregate measures of poverty and unemployment and find similar results (not shown).

Due to our exclusion criteria, our analytic sample was slightly more advantaged than the full Add Health sample, potentially underestimating the impact of disadvantage on obesity. However, this gives us confidence in the importance of the effects we do find, given they may be more conservative. In addition, the lack of a parallel neighborhood-level measure of parent education of high school or less means comparisons with aggregate measures of parent education at the schoolor peer-level should be interpreted with caution. However, sensitivity analysis using aggregate measures of poverty and unemployment produced similar results, providing some confidence in our conclusions.

We also cannot capture factors related to the incidence of obesity prior to adolescence. Therefore, we cannot be certain that additional contextual measures not captured in adolescence are related to obesity incidence in adolescence and young adulthood. However, it should be noted that about $12 \%$ of the sample became obese between WII and WIII. In addition, our inclusion of a lagged measure of obesity in adolescence when examining obesity in young adulthood helps to account for the greater risk of obesity in young adulthood among individuals already obese in adolescence. 
Last, our use of secondary analysis precludes including important measures that might be associated with obesity and disadvantage that are not included in the Add Health data, such as school policies and programs associated with eating behavior and physical activity. Only through primary data collection could these additional measures be obtained, but it is unlikely that data on the large scale available from Add Health could be readily collected. It should also be noted that there are additional risk factors for obesity that were not included in this analysis, such as genetic propensity (although a control for parental obesity helps to account for this), and personal attributes such as self-efficacy. However, the inclusion of these measures was beyond the scope of these analyses.

Strengths of this study include use of a nationally representative sample of individuals with racial/ethnic and socioeconomic diversity; sophisticated multilevel methodology; and the longitudinal design over multiple time points, which distinguish the changing role of social context on obesity in the transition from adolescence into adulthood.

\section{Conclusions}

A large body of research has identified contextual disadvantage as an important underlying determinant of obesity, as well as other health outcomes. Although this research has identified the relation between school-level disadvantage and adolescent obesity, future research should examine the mechanisms which account for these associations. Understanding the unique barriers to physical activity and healthy eating in disadvantaged schools will be a particularly important direction for policy research and evaluation. In addition, future research should continue to disentangle what contexts are most salient for obesity prevention and intervention strategies across the life course, particularly among vulnerable populations.

\section{IMPLICATIONS FOR SCHOOL HEALTH}

Although family-, peer-, school-, and neighborhood-level disadvantage are associated with obesity in both adolescence and young adulthood, when all levels of disadvantage were considered simultaneously, only school-level disadvantage was associated with obesity in adolescence, and only family-level disadvantage was associated with obesity in young adulthood. There has been a recent emphasis on the school context for reducing obesity risks by limiting the availability of snacks and drinks with high sugar and salt content (eg, soda), but critics have argued that returning to a family context that promotes poor diet and other behaviors associated with obesity risk undermines such policies. ${ }^{56}$ Our findings are one of the first to indicate that the school context matters over and above the influence of the family, for potentially reducing obesity among adolescents, particularly among disadvantaged populations. ${ }^{57}$ Adolescents spend a majority of time in school, may eat several meals and engage in physical activity during this time, and, therefore, time spent in school represents a significant opportunity to influence adolescent development of health and lifestyle behaviors that often persist into adulthood. It will be important to develop health programs tailored to the needs of schools serving disadvantaged populations to reduce the incidence and persistence of socioeconomic disparities in obesity. There is small, but growing, evidence that school-based obesity prevention interventions that include physical activity, nutrition, and healthy lifestyle components, along with modifications to school-provided meals are associated with improvements in health and health behaviors, including reductions in BMI. ${ }^{58,59}$ School programming efforts need funding and incentives to make the changes necessary to address adolescent obesity in disadvantaged schools. Efforts like the Let's Move campaign may help to facilitate these endeavors. ${ }^{60}$

\section{Human Subjects Approval Statement}

The analysis of this de-identified data received human subjects approval from the University of Washington and the University of North CarolinaChapel Hill.

\section{REFERENCES}

1. Kumanyika S, Grier S. Targeting interventions for ethnic minority and low-income populations. Future Child. 2006;16(1):187-207.

2. Saporito S, Sohoni D. Mapping educational inequality: concentrations of poverty among poor and minority students in public schools. Soc Forces. 2007;85(3):1227-1253.

3. Eisenberg ME, Neumark-Sztainer D, Story M, Perry C. The role of social norms and friends' influences on unhealthy weight-control behaviors among adolescent girls. Soc Sci Med. 2005;60(6):1165-1173.

4. Balaji AB, Brener ND, McManus T. Variation in school health policies and programs by demographic characteristics of US schools, 2006. J Sch Health. 2010;80(12):599-613.

5. Lovasi GS, Hutson MA, Guerra M, Neckerman KM. Built environments and obesity in disadvantaged populations. Epidemiol Rev. 2009;31(1):7-20.

6. Bronfenbrenner U. The Ecology of Human Development: Experiments by Nature and Design. Cambridge, MA: Harvard University Press; 1979.

7. Jencks C, Mayer SE. The social consequences of growing up in a poor neighborhood. In: Elder GH Jr, McGeary MGH, eds. Inner-City Poverty in the United States. Washington, DC: National Academy Press; 1990.

8. Miech RA, Kumanyika SK, Stettler N, Link BG, Phelan JC, Chang VW. Trends in the association of poverty with overweight among US adolescents, 1971-2004. JAMA. 2006;295(20):2385-2393.

9. Lee H, Harris K, Gordon-Larsen P. Life course perspectives on the links between poverty and obesity during the transition to young adulthood. Popul Res Policy Rev. 2009;28(4):505-532. 
10. Greves Grow HM, Cook AJ, Arterburn DE, Saelens BE, Drewnowski A, Lozano P. Child obesity associated with social disadvantage of children's neighborhoods. Soc Sci Med. 2010;71(3):584-591.

11. Wickrama TKA, Wickrama K, Bryant C. Community influence on adolescent obesity: race/ethnic differences. J Youth Adolesc. 2006;35(4):641-651.

12. Janssen I, Boyce WF, Simpson K, Pickett W. Influence of individual- and area-level measures of socioeconomic status on obesity, unhealthy eating, and physical inactivity in Canadian adolescents. Am J Clin Nutr. 2006;83(1):139-145.

13. Richmond TK, Subramanian SV. School level contextual factors are associated with the weight status of adolescent males and females. Obesity. 2008;16(6):1324-1330.

14. O'Malley PM, Johnston LD, Delva J, Bachman JG, Schulenberg JE. Variation in obesity among American secondary school students by school and school characteristics. Am J Prev Med. 2007;33(suppl 4):S187-S194.

15. Vieweg VR, Johnston CH, Lanier JO, Fernandez A, Pandurangi AK. Correlation between high risk obesity groups and low socioeconomic status in school children. South Med J. 2007;100(1):8-13.

16. Halliday TJ, Kwak S. Weight gain in adolescents and their peers. Econ Hum Biol. 2009;7(2):181-190.

17. Fowler JH, Christakis NA. Estimating peer effects on health in social networks: a response to Cohen-Cole and Fletcher; and Trogdon, Nonnemaker, and Pais. J Health Econ. 2008;27(5):1400-1405

18. Carter MA, Dubois L. Neighbourhoods and child adiposity: a critical appraisal of the literature. Health Place. 2010; 16(3):616-628.

19. Elder GH Jr. The life course as developmental theory. Child Dev. 1998;69(1):1-12.

20. Elder GH, Eccles JS, Ardelt M, Lord S. Inner-city parents under economic pressure: perspectives on the strategies of parenting. J Marriage Fam. 1995;57(3):771-784.

21. Dietz WH, Gortmaker SL. Preventing obesity in children and adolescents. Annu Rev Public Health. 2001;22(1):337-353.

22. Dietz W. Critical periods in childhood for the development of obesity. Am J Clin Nutr. 1994;59:955-959.

23. Gordon-Larsen P, Adair LS, Nelson MC, Popkin BM. Five-year obesity incidence in the transition period between adolescence and adulthood: the National Longitudinal Study of Adolescent Health. Am J Clin Nutr. 2004;80(3):569-575.

24. Harris KM, Gordon-Larsen P, Chantala K, Udry JR. Longitudinal trends in race/ethnic disparities in leading health indicators from adolescence to young adulthood. Arch Pediatr Adolesc Med. 2006;160(1):74-81.

25. Serdula MK, Ivery D, Coates RJ, Freedman DS, Williamson DF, Byers T. Do obese children become obese adults? a review of the literature. Prev Med. 1993;22(2):167.

26. Dietz WH. Health consequences of obesity in youth: childhood predictors of adult disease. Pediatr. 1998;101 (suppl 2):518-525.

27. Gortmaker SL, Must A, Perrin JM, Sobol AM, Dietz WH. Social and economic consequences of overweight in adolescence and young adulthood. $N$ Engl J Med. 1993;329(14):1008-1012.

28. Guo SS, Wu W, Chumlea WC, Roche AF. Predicting overweight and obesity in adulthood from body mass index values in childhood and adolescence. Am J Clin Nutr. 2002;76(3):653-658.

29. Guo G, Zhao H. Multilevel modeling for binary data. Annu Rev Sociol. 2000;26(1):441-462.

30. Harris KM, Florey F, Tabor JW, Bearman PS, Jones J, Udry JR. The National Longitudinal Study of Adolescent Health: research design. 2009. Available at: http://www.cpc. unc.edu/projects/addhealth/design. Accessed October 18, 2008.

31. Elgar FJ, Roberts C, Tudor-Smith C, Moore L. Validity of selfreported height and weight and predictors of bias in adolescents. $J$ Adolesc Health. 2005;37(5):371-375.
32. Gorber SC, Tremblay M, Moher D, Gorber B. A comparison of direct vs. self-report measures for assessing height, weight and body mass index: a systematic review. Obes Rev. 2007;8(4):307-326.

33. Cole TJ, Bellizzi MC, Flegal KM, Dietz WH. Establishing a standard definition for child overweight and obesity worldwide: international survey. BMJ. 2000;320(7244):1240-1243.

34. Whitaker RC, Wright JA, Pepe MS, Seidel KD, Dietz WH. Predicting obesity in young adulthood from childhood and parental obesity. N Engl J Med. 1997;337(13):869-873.

35. LaVeist T. Disentangling race and socioeconomic status: a key to understanding health inequalities. J Urban Health. 2005;82(0):iii26-iii34.

36. Cutler DM, Lleras-Muney A. Education and health: evaluating theories and evidence. In: Schoeni RF, House JS, Kaplan G, Pollack H, eds. Making Americans Healthier: Social and Economics Policy as Health Policy. New York, NY: Russell Sage Foundation; 2008.

37. Currie J. Healthy, wealthy, and wise: socioeconomic status, poor health in childhood, and human capital development. $J$ Econ Lit. 2009;47(1):87-122.

38. Trogdon JG, Nonnemaker J, Pais J. Peer effects in adolescent overweight. J Health Econ. 2008;27(5):1388-1399.

39. Drewnowski A, Specter S. Poverty and obesity: the role of energy density and energy costs. Am J Clin Nutr. 2004; 79(1):6-16.

40. Moore JC, Stinson LL, Welniak EJ Jr. Income measurement error in surveys: a review. J Off Stat. 2000;16(4):331-361.

41. U.S. Census Bureau, Geography Division. Geographic areas reference manual. Geography Division, Bureau of the Census, Washington, DC. Available at: http://www.census. gov/geo/www/garm.html. Accessed October 18, 2009.

42. Tickamyer AR, Duncan CM. Poverty and opportunity structure in rural America. Annu Rev Sociol. 1990;16:67-86.

43. Davis AM, Bennett KJ, Befort C, Nollen N. Obesity and related health behaviors among urban and rural children in the United States: data from the National Health and Nutrition Examination Survey 2003-2004 and 2005-2006. J Pediatr Psychol. 2011;36(6):669-676.

44. Richmond TK, Hayward RA, Gahagan S, Field AE, Heisler $M$. Can school income and racial/ethnic composition explain the racial/ethnic disparity in adolescent physical activity participation? Pediatrics. 2006;117(6):2158-2166.

45. Wang Y, Beydoun MA. The obesity epidemic in the United States-gender, age, socioeconomic, racial/ethnic, and geographic characteristics: a systematic review and metaregression analysis. Epidemiol Rev. 2007;29(1):6-28.

46. National Center for Education Statistics (NCES). Characteristics of the 100 largest public elementary and secondary school districts in the United States: 2004-05, NCES, Washington, DC. Available at: http://nces.ed.gov/pubs2008/ 100_largest/tables/table_02.asp. Accessed October 18, 2010.

47. Sirin SR. Socioeconomic status and academic achievement: a meta-analytic review of research. Rev Educ Res. 2005;75(3):417-453.

48. Koplan JP, Liverman CT, Kraak VI, eds. Preventing Childhood Obesity: Health in the Balance. Washington, DC: National Academies Press; 2005.

49. Zhang Q, Wang Y. Trends in the association between obesity and socioeconomic status in U.S. Adults: 1971 to 2000. Obesity Res. 2004;12:1622.

50. Williams DR. The health of men: structured inequalities and opportunities. Am J Public Health. 2003;93(5):724-731.

51. Jackson JS, Knight KM. Race and self-regulatory health behaviors: the role of the stress response and the HPA axis in physical and mental health disparities. In: Schaie KW, Carstensen L, eds. Social Structure Aging and Self-Regulation in the Elderly. New York, NY: Springer Publishing Company; 2006:189-239. 
52. Richmond TK, Subramanian SV. School variation in asthma: compositional or contextual? PLoS One. 2009;4(12): e8512.

53. Goodman E, Huang B, Wade TJ, Kahn RS. A multilevel analysis of the relation of socioeconomic status to adolescent depressive symptoms: does school context matter? J Pediatr. 2003;143(4):451-456.

54. Evans WN, Oates WE, Schwab RM. Measuring peer group effects: a study of teenage behavior. $J$ Polit Econ. 1992;100(5):966-991.

55. Duncan GJ, Raudenbush SW. Assessing the effects of context in studies of child and youth development. Educ Psychol. 1999;34(1):29-41.

56. Gunlock J. Children, parents, and obesity. National Affairs. 2011; Winter(6):86-104.

57. Li J, Hooker NH. Childhood obesity and schools: evidence from the National Survey of Children's Health. J Sch Health. 2010;80(2):96-103.
58. Hollar D, Lombardo M, Lopez-Mitnik G, et al. Effective multi-level, multi-sector, school-based obesity prevention programming improves weight, blood pressure, and academic performance, especially among low-income, minority children. $J$ Health Care Poor Underserved. 2010;21(2):93-108.

59. Prelip M, Slusser W, Thai CL, Kinsler J, Erausquin JT. Effects of a school-based nutrition program diffused throughout a large urban community on attitudes, beliefs, and behaviors related to fruit and vegetable consumption. J Sch Health. 2011;81(9):520-529.

60. The White House Office of the First Lady. First Lady Michelle Obama launches Let's Move: America's move to raise a healthier generation of kids. 2010. Available at: http://www.whitehouse. gov/the-press-office/first-lady-michelle-obama-launches-letsmove-americas-move-raise-a-healthier-genera. Accessed June 5, 2012 . 